\title{
Trends in service use and treatment for mental disorders in adults throughout Great Britain
}

\author{
TRAOLACH S. BRUGHA, PAUL E. BEBBINGTON, NICOLA SINGLETON, \\ DAVID MELZER, RACHEL JENKINS, GLYN LEWIS, MICHAEL FARRELL, \\ DINESH BHUGRA, ALISON LEE and HOWARD MELTZER
}

\begin{abstract}
Background Trends in health treatments and outcomes in the general population may be used to monitor achievement of health targets.
\end{abstract}

\begin{abstract}
Aims To investigate changes in mental health services and treatment in Britain over a 7-year period.
\end{abstract}

Method National surveys of psychiatric morbidity were completed in 1993 and 2000 in households throughout Great Britain. Standardised interviews were used to establish psychiatric case status and service and treatment utilisation in adults aged $16-64$ years.

Results Use of psychotropic medication doubled in those designated as psychiatric cases. In the non-case-status population antidepressant use rose from $0.16 \%$ in 1993 (95\% Cl 0.07-0.25) to $2.02 \%$ in 2000 (95\% Cl I.69-2.35). However, the overall prevalence of neurotic and psychotic disorder hardly changed from 1993 to 2000. Use of specialised 'talking treatments' did not increase significantly, except in the non-case group.

\section{Conclusions Treatment with psychotropic medication alone is unlikely to improve the overall mental health of the nation. A policy based almost exclusively on treatment of identified cases should be augmented by preventive approaches.}

Declaration of interest None. Funding detailed in Acknowledgement.
National mental health strategies must set realistic targets for improvements in the mental health of the population (Jenkins et al, 2002). Despite the high prevalence rates of common mental disorders, these conditions have traditionally been underdetected and undertreated (Goldberg \& Huxley, 1992). In recent years changes in services should have improved this situation in Great Britain. A joint campaign by the Royal College of General Practitioners and the Royal College of Psychiatrists to increase awareness and the effective treatment of depression (Paykel et al, 1997) led to over half of general practitioners taking part in teaching sessions on depression. The pharmaceutical industry has successfully encouraged increased prescription of newer antidepressants (Donoghue et al, 1996). The effectiveness of such innovations may be evaluated by monitoring the mental health and treatment of representative samples of the whole population. Our study was designed to investigate trends in treatment and services in relation to mental health functioning over the 7-year period 1993-2000.

\section{METHOD}

Psychiatric morbidity surveys of the general population of Great Britain took place in 1993 (Jenkins et al, 1997) and in 2000 (Singleton et al, 2001). Information was obtained by structured survey interviews carried out with national probability samples of households. No information was collected directly from services. The 2000 survey reported no significant change in the prevalence of psychiatric disorder compared with 1993 (Singleton et al, 2001; Ferriman, 2001). This paper reports on trends in treatment and services received by adults according to the presence of common and severe mental disorders, comparing data for 1993 and 2000 in Great Britain.
In both surveys delivery points were randomly drawn from postal sectors of the Small Area Postcode Address File, stratifying for socio-economic grouping within the English regions, Wales and Scotland. In the 2000 survey, 12792 adults aged 16-74 years were selected from 14285 eligible households at 15804 delivery points; in the 1993 survey, 12730 adults aged 16-64 were selected from 15765 private households located at 18000 delivery points. The percentage of adults cooperating was $80 \%$ in 1993 and $69 \%$ in 2000 . In 2000 the upper age limit for respondents was extended from 64 years to 74 years; to permit direct comparison, only data for respondents aged 16-64 years are used in this paper. The Highlands and Islands of Scotland were excluded in 1993 but not in 2000. In 2000, computerassisted interviewing replaced the paper and pencil questionnaires used in 1993. In both surveys, standardised questions were asked covering employment and education, marital status and age, ethnic origin, general health, access to health services and treatment received for general health and mental health problems.

The surveys collected information about medication being taken on prescription by informants at the time of interview. Findings were cross-checked against Office for National Statistics (ONS) analyses of morbidity and prescribing trends (19941998) collected through the General Practice Research Database (GPRD), which was originally set up in 1987 (Office for National Statistics, 2000). All household survey respondents were asked the question: 'Are you taking any pills or tablets or any other medicine by mouth which have been prescribed for you'? The medicines were coded at interview in the 2000 survey and during data entry subsequent to the interview in the 1993 survey according to British National Formulary categories (British Medical Association \& Royal Pharmaceutical Society of Great Britain, 2000). The following categories of medication used in the treatment of psychiatric disorders were considered in the two household surveys:

(a) drugs used for the treatment of psychotic illness, including antipsychotic drugs, antipsychotic depot injections and antimanic drugs;

(b) antidepressants;

(c) hypnotics and anxiolytics. 
The surveys collected information about talking treatments for mental health problems. Respondents were handed a show-card listing these interventions and asked:

'Looking at this card, could you tell me if you are having any counselling or therapy for a mental, nervous or emotional problem either at home, at a doctor's surgery, a health centre, hospital or clinic?'

These other forms of treatment were grouped into two broad categories: therapy and counselling. These included psychotherapy, behavioural or cognitive therapy, art music or drama therapy, social skills training, marital or family therapy, sex therapy and counselling.

Although we also collected details of the use of health and other services, this analysis considers only general practice consultations. Respondents were asked:

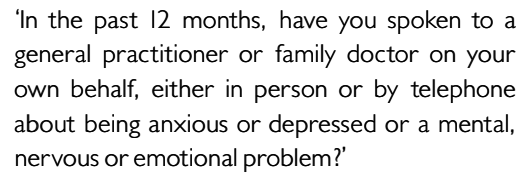
general practitioner or family doctor on your own behalf, either in person or by telephone about being anxious or depressed or a mental, nervous or emotional problem?'

The same question was repeated for 'a physical problem' in the past year. We also asked about contact with a general practitioner or family doctor for any reason in the previous 2 weeks.

In order to examine the relation between mental disorder and treatment, the Revised Clinical Interview Schedule (CIS-R; Lewis et al, 1992) was used in both surveys, with one modification in 2000: in 1993 questions on suicidal thoughts and attempts were only asked of people with symptoms of depression in the past year, whereas they were asked of everyone at the end of the CIS-R in 2000 and a slightly broader range of questions was used. The CIS-R also provides prevalences of individual disorders relating to a 1 -week period. Basic symptom data were subjected to a computer algorithm providing diagnostic categories according to ICD-10 (World Health Organization, 1993). Individuals who scored above threshold on the Psychosis Screening Questionnaire (PSQ; Bebbington \& Nayani, 1995), or who reported that they were taking antipsychotic medication or that they had been given a diagnosis of psychotic illness by a doctor, were given a second interview as soon afterwards as possible by clinicians trained in the Schedules for Clinical Assessment in Neuropsychiatry (SCAN; Wing et al, 1990). In the absence of a SCAN interview, a project diagnosis of 'probable functional psychosis' was still made for anyone fulfilling all three screening criteria. The criteria used to screen for a secondstage interview for psychotic disorders were changed in 2000 but, to permit comparison between the two surveys, the 1993 screening approach was applied to the 2000 survey data to identify people who would have been selected for a SCAN in 1993. Probable functional psychosis was categorised in the same way in both surveys.

In the two samples we compared the use of services and treatments in those with and without psychiatric disorders, as defined above. Analyses based on weighted data were performed using STATA 6.0 (STATA, 1999), which allows the use of data modified by probability weights and takes account of sample clustering. We compared weighted percentages and calculated percentage differences with $95 \%$ confidence intervals for treatment and service use by survey diagnosis in 1993 and 2000 . True standard errors for the observed percentages and for the percentage differences observed between 1993 and 2000 were calculated according to a formula taking account of the effect of using complex sampling designs (Singleton et al, 2001: Appendix A2).

\section{RESULTS}

Between 1993 and 2000 the use of psychotropic medication increased significantly in those with any neurotic disorder (Table 1), particularly in those with depressive disorder or generalised anxiety disorder. The most striking increases were in the use of antidepressants in the treatment of depression, with a doubling in women from $18 \%(95 \%$ CI $11-25)$ in 1993 to $36 \%$ $(95 \%$ CI $27-45)$ in 2000 , and an almost threefold increase in men from $12 \%(95 \%$ CI 6-18) in 1993 to $34 \%$ (95\% CI $23-$ 44 ) in 2000 . There was thus a suggestion that increases were dependent on gender, i.e. a greater increase occurred in men than in women, but in general these were not statistically significant interactions. Use of antipsychotic medication for those with probable psychosis increased from $35 \%$ in 1993 to $57 \%$ in 2000 , but this increase was not statistically significant. There was also increased use of other central nervous system medication, principally in the form of analgesics. Although the use of antidepressants and anxiolytic/hypnotic preparations in people with no current psychiatric disorder was rare, there were significant and striking increases in the use of these drugs between the two surveys. Antidepressant use by people with no current disorder rose from just above zero $(0.16 \%)$ in 1993 (95\% CI $0.07-0.25)$ to $2.02 \%$ in 2000 (95\% CI $1.69-2.35 \%$ ), i.e. approximately 20200 people who were taking these drugs had no current disorder.

For comparison purposes, prescribing of antidepressants was also cross-checked against ONS analyses of UK morbidity and prescribing trends over the shorter period 1994-1998 collected through the GPRD practices (Office for National Statistics, 2000). The number of men prescribed selective serotonin reuptake inhibitors (SSRIs) per 1000 patient-years (age-standardised, all ages) rose from 8.5 to 19.5 ; in women it rose from 18.7 to 42.6 per 1000 patient years in the same 4-year period. At

Table I Temporal differences in psychotropic medication use in those with any neurotic disorder

\begin{tabular}{|c|c|c|c|c|c|}
\hline & \multirow{2}{*}{$\begin{array}{c}\text { 1993' } \\
\% \text { (adj) }\end{array}$} & \multirow{2}{*}{$\begin{array}{c}2000^{2} \\
\%(\mathrm{adj})\end{array}$} & \multicolumn{3}{|c|}{ Difference } \\
\hline & & & $\%$ & $95 \% \mathrm{Cl}$ & $P$ \\
\hline \multicolumn{6}{|l|}{ Women } \\
\hline Hypnotics and anxiolytics & 3.98 & 4.60 & 0.62 & -1.06 to 2.29 & NS \\
\hline Antidepressants & 6.56 & 17.52 & 10.97 & 8.10 to 13.84 & $<0.01$ \\
\hline Any psychotropic medication & 9.56 & 20.11 & 10.55 & 7.48 to 13.62 & $<0.01$ \\
\hline \multicolumn{6}{|l|}{ Men } \\
\hline Hypnotics and anxiolytics & 4.24 & 7.26 & 3.02 & 0.02 to 6.02 & $<0.05$ \\
\hline Antidepressants & 4.79 & 14.64 & 9.85 & 5.87 to 13.82 & $<0.01$ \\
\hline Any psychotropic medication & 9.74 & 19.07 & 9.33 & 4.81 to 13.85 & $<0.01$ \\
\hline
\end{tabular}

adj, adjusted.

I. Sample sizes: women II06, men 607

2. Sample sizes: women 863 , men 513 . 
the same time, there was no fall in the number of persons prescribed other (i.e. principally tricyclic) antidepressants (males 22 to 24.5 , females 47.9 to 49.5 ) between 1994 and 1998. Prescriptions of anxiolytics and hypnotics remained virtually static in men and women. Information on general practitioner diagnosis of depression, which could not be assessed in the household surveys, was also recorded in the GPRD. The age-standardised prevalence rate of those with treated depression per 1000 patient-years rose from 19.9 in 1994 to 29.0 in 1998 in males; in females it rose from 50.5 to 70.1 . The prevalence of treated depression increased in all age groups in both genders and the only type of medication increasingly prescribed was of the SSRI type.

Significant increases in the use of psychological therapies and counselling for those with neurotic disorder were not found (Table 2), with two exceptions: behavioural or cognitive therapy and the 'other therapy' category, both in men only. Use of family, marital and sex therapy did not change significantly. There were statistically significant decreases in women in the use of 'art, music or drama therapy' and in 'social skills training', both therapies almost disappearing from use. Although there were non-significant trends towards an increased use of therapies, particularly in respondents with depression, $95 \%$ confidence intervals were wide. However, the use of any form of counselling or therapy in those without a disorder did increase significantly from $0.2 \%(95 \%$ CI $0.1-0.3)$ to $1.2 \%$ (95\% CI $0.9-1.5)$. This was accounted for by significant increases by those without a disorder in the use of psychotherapy (up from $0.1 \%$ to $0.4 \%$ ) and of 'other therapy' (up from $0 \%$ to $0.2 \%$ ).

Contacts with a general practitioner for a mental or emotional reason within the year before interview were essentially unchanged between the two surveys in those without neurotic disorder (Table 3). There was, however, a significant trend for an increase in general practitioner contact in the past year for a mental problem in those with neurotic disorder (increasing significantly from $35 \%$ to $40 \%$ ). This was particularly noticeable in the case of women with depression (increasing from $51 \%$ to $71 \%$ ); this increase was mirrored in a significant trend for reduced contact in the past year for a physical problem in all adults with neurotic disorder, which was not significant in women with depression (Table 3). There was also reduced general practitioner contact in the past year for a physical problem in all adults that was significant in those without a neurotic disorder (a drop from $66 \%$ to $62 \%$ ). Unfortunately, the survey data on general

Table 2 Temporal differences in therapies and counselling for those with any neurotic disorder

\begin{tabular}{|c|c|c|c|c|c|}
\hline & \multirow{2}{*}{$\begin{array}{c}\text { I993' } \\
\% \text { (adj) }\end{array}$} & \multirow{2}{*}{$\begin{array}{l}2000^{2} \\
\% \text { (adj) }\end{array}$} & \multicolumn{3}{|c|}{ Difference } \\
\hline & & & $\%$ & $95 \% \mathrm{Cl}$ & $P$ \\
\hline \multicolumn{6}{|l|}{ Women } \\
\hline Psychotherapy & 2.93 & 1.82 & -1.12 & -2.46 to 0.23 & NS \\
\hline Behavioural or cognitive therapy & 0.67 & 0.52 & -0.15 & -0.92 to 0.62 & NS \\
\hline Art, music or drama therapy & 0.73 & 0.07 & -0.66 & -1.28 to -0.04 & $<0.05$ \\
\hline Social skills training & 0.88 & 0.05 & -0.83 & -1.49 to -0.17 & $<0.05$ \\
\hline Counselling & 3.68 & 5.27 & 1.59 & -0.34 to 3.53 & NS \\
\hline Other therapy & 0.69 & 0.61 & -0.08 & -0.86 to 0.70 & NS \\
\hline Any psychological therapy & 6.70 & 7.93 & 1.23 & -1.22 to 3.68 & NS \\
\hline \multicolumn{6}{|l|}{ Men } \\
\hline Psychotherapy & 2.88 & 4.45 & 1.57 & -0.97 to 4.10 & NS \\
\hline Behavioural or cognitive therapy & 0.17 & 1.21 & 1.04 & 0.07 to 2.01 & $<0.05$ \\
\hline Art, music or drama therapy & 0.08 & 0.56 & 0.48 & -0.26 to $1.2 \mathrm{I}$ & NS \\
\hline Social skills training & 0.17 & 0.10 & -0.06 & -0.37 to 0.25 & NS \\
\hline Counselling & 3.25 & 3.51 & 0.26 & -1.92 to 2.44 & NS \\
\hline Other therapy & 0.08 & 1.56 & 1.48 & 0.31 to 2.64 & $<0.05$ \\
\hline Any psychological therapy & 6.20 & 9.80 & 3.60 & -0.04 to 7.23 & NS \\
\hline
\end{tabular}

adj, adjusted.

I. Sample sizes: women II06, men 607.

2. Sample sizes: women 863 , men 513 . practitioner contact for any reason covered only the past 2 weeks; this generally showed a reduction in contact (significant in adults with no neurotic disorder), with the exception of a non-significant increase in such recent contacts in those with psychosis (Table 3).

In general, rates of neurotic disorder and levels of neurotic symptoms did not alter significantly between 1993 and 2000 (Fig. 1). If anything, there was a suggestion of a skew in older men towards higher scores: an increase in those exceeding the CIS-R threshold was due to particularly high symptom scorers (CIS-R total score $>18$ ). In men overall, there was a significantly increased prevalence of high neurotic symptom scores (CIS-R 18+ from 5\% to $7 \%)$ and of specific neurotic disorders (13\% to $14 \%)$. Detailed tables describing trends in rates of psychiatric disorder from 1993 to 2000 have been published (Singleton et al, 2001), showing that the prevalence of psychotic disorder was also unchanged: 4 cases per 1000 in 1993 and in 2000 based on the same methods of ascertainment.

\section{DISCUSSION}

We found some evidence of increased frequency of contact with general practitioners in the past year for a mental problem by those with neurotic disorders and of substantially increased use of antidepressant medication. However, there was no significant increase in the use of specialised 'talking treatments' in those with a psychiatric disorder in spite of growing emphasis on this in National Health Service policy (Roth \& Fonagy, 1996). The prevalence of neurotic and psychotic disorders was unchanged between 1993 and 2000 (Singleton et al, 2001).

Between the two survey years, usage of antidepressants at the point of survey interview rose from an estimated 10900 to 44900 persons per million of the population. In the non-case group, usage increased from an estimated 1600 to 20200 , despite the fact that these people were largely free of neurotic symptoms during the 2 weeks prior to interview. This accounts for a considerable part of the overall increase in use (and of dispensed prescriptions) and therefore the cost of such medication. The GPRD data show that the number of prescriptions for antidepressants by GPRD practices exceeds the treated 
Table 3 Temporal differences in general practitioner visits in adults with neurotic disorder

\begin{tabular}{|c|c|c|c|c|c|c|c|c|c|}
\hline \multirow[t]{2}{*}{ Base } & \multirow[t]{2}{*}{ Disorder } & \multirow[t]{2}{*}{ Treatment } & \multicolumn{2}{|c|}{1993} & \multicolumn{2}{|c|}{2000} & \multirow{2}{*}{$\begin{array}{c}\text { Difference } \\
\%\end{array}$} & \multirow[t]{2}{*}{$95 \% \mathrm{Cl}$} & \multirow[t]{2}{*}{$P$} \\
\hline & & & $\%$ (adj) & $\begin{array}{l}\text { Sample } \\
\text { size }(n)\end{array}$ & \% (adj) & $\begin{array}{l}\text { Sample } \\
\text { size }(n)\end{array}$ & & & \\
\hline \multirow[t]{3}{*}{ All adults } & Probable psychosis & $\begin{array}{l}\text { Spoken to GP in past year - } \\
\text { physical problem }\end{array}$ & 69.01 & 53 & 64.82 & 36 & -4.19 & -25.37 to 16.98 & NS \\
\hline & & $\begin{array}{l}\text { Spoken to GP in past year - } \\
\text { mental problem }\end{array}$ & 63.33 & 53 & 69.01 & 36 & 5.69 & -15.95 to 27.32 & NS \\
\hline & & $\begin{array}{l}\text { Spoken to GP in past 2-weeks - } \\
\text { any reason }\end{array}$ & 11.67 & 53 & 18.25 & 36 & 6.58 & -8.95 to 22.11 & NS \\
\hline \multirow[t]{3}{*}{ Women } & Depression & $\begin{array}{l}\text { Spoken to GP in past year - } \\
\text { physical problem }\end{array}$ & 75.70 & 158 & 69.20 & 143 & -6.50 & -16.80 to 3.80 & NS \\
\hline & & $\begin{array}{l}\text { Spoken to GP in past year - } \\
\text { mental problem }\end{array}$ & 50.85 & 165 & 70.51 & 143 & 19.67 & 7.68 to 31.66 & 0.01 \\
\hline & & $\begin{array}{l}\text { Spoken to GP in past } 2 \text { weeks - } \\
\text { any reason }\end{array}$ & 19.98 & 158 & 18.70 & 143 & -1.28 & $-\mathrm{II} . \mathrm{II}$ to 8.55 & NS \\
\hline \multirow[t]{3}{*}{ Men } & Depression & $\begin{array}{l}\text { Spoken to GP in past year - } \\
\text { physical problem }\end{array}$ & 53.44 & 93 & 53.67 & 97 & 0.23 & -15.38 to 15.84 & NS \\
\hline & & $\begin{array}{l}\text { Spoken to GP in past year - } \\
\text { mental problem }\end{array}$ & 41.77 & 98 & 54.73 & 97 & 12.96 & -3.28 to 29.20 & NS \\
\hline & & $\begin{array}{l}\text { Spoken to GP in past } 2 \text { weeks - } \\
\text { any reason }\end{array}$ & 23.22 & 93 & $|2.4|$ & 97 & -10.80 & -21.94 to 0.34 & NS \\
\hline \multirow[t]{3}{*}{ Women } & $\begin{array}{l}\text { Generalised anxiety } \\
\text { disorder }\end{array}$ & $\begin{array}{l}\text { Spoken to GP in past year - } \\
\text { physical problem }\end{array}$ & 63.88 & 284 & 62.71 & 224 & -1.17 & -9.27 to 6.92 & NS \\
\hline & & $\begin{array}{l}\text { Spoken to GP in past year - } \\
\text { mental problem }\end{array}$ & 49.72 & 298 & 55.43 & 224 & 5.71 & -3.61 to 15.02 & NS \\
\hline & & $\begin{array}{l}\text { Spoken to GP in past } 2 \text { weeks - } \\
\text { any reason }\end{array}$ & 14.78 & 285 & 11.66 & 224 & -3.12 & -9.47 to 3.24 & NS \\
\hline \multirow[t]{3}{*}{ Men } & $\begin{array}{l}\text { Generalised anxiety } \\
\text { disorder }\end{array}$ & $\begin{array}{l}\text { Spoken to GP in past year - } \\
\text { physical problem }\end{array}$ & 65.20 & 186 & 56.97 & 173 & -8.23 & -18.74 to 2.29 & NS \\
\hline & & $\begin{array}{l}\text { Spoken to GP in past year - } \\
\text { mental problem }\end{array}$ & 35.30 & 193 & 45.21 & 173 & 9.91 & -1.23 to 21.05 & NS \\
\hline & & $\begin{array}{l}\text { Spoken to GP in past } 2 \text { weeks - } \\
\text { any reason }\end{array}$ & 18.96 & 186 & 13.01 & 173 & -5.95 & -14.20 to 2.30 & NS \\
\hline \multirow[t]{3}{*}{ All adults } & $\begin{array}{l}\text { No neurotic } \\
\text { disorder }\end{array}$ & $\begin{array}{l}\text { Spoken to GP in past year - } \\
\text { physical problem }\end{array}$ & 65.45 & 7901 & 62.26 & 5935 & -3.18 & -5.00 to -1.36 & $<0.01$ \\
\hline & & $\begin{array}{l}\text { Spoken to GP in past year - } \\
\text { mental problem }\end{array}$ & 7.27 & 8111 & 6.69 & 5934 & -0.58 & -1.50 to 0.35 & NS \\
\hline & & $\begin{array}{l}\text { Spoken to GP in past } 2 \text { weeks - } \\
\text { any reason }\end{array}$ & 17.33 & 7915 & 13.13 & 5936 & -4.20 & -5.49 to -2.92 & $<0.01$ \\
\hline \multirow[t]{3}{*}{ All adults } & $\begin{array}{l}\text { Any neurotic } \\
\text { disorder }\end{array}$ & $\begin{array}{l}\text { Spoken to GP in past year - } \\
\text { physical problem }\end{array}$ & 64.17 & 1656 & 60.58 & 1375 & -3.60 & -7.28 to 0.08 & NS \\
\hline & & $\begin{array}{l}\text { Spoken to GP in past year - } \\
\text { mental problem }\end{array}$ & 35.40 & 1712 & 39.67 & 1376 & 4.26 & 0.36 to 8.16 & $<0.05$ \\
\hline & & $\begin{array}{l}\text { Spoken to GP in past } 2 \text { weeks - } \\
\text { any reason }\end{array}$ & 18.08 & 1657 & 13.26 & 1376 & -4.82 & -7.70 to -1.94 & $<0.01$ \\
\hline
\end{tabular}

adj, adjusted; GP, general practitioner.

prevalence (although dual therapy could account for this), although this excess has not altered over the shorter period 19941998. We did not include in the surveys questions on a past history of depression or psychiatric disorder; thus, we cannot say how many of these treatments were intended to prevent relapse by people in remission. The pharmaceutical industry and the psychiatric profession have joined in encouraging the prophylactic use of antidepressants in the interval between the 


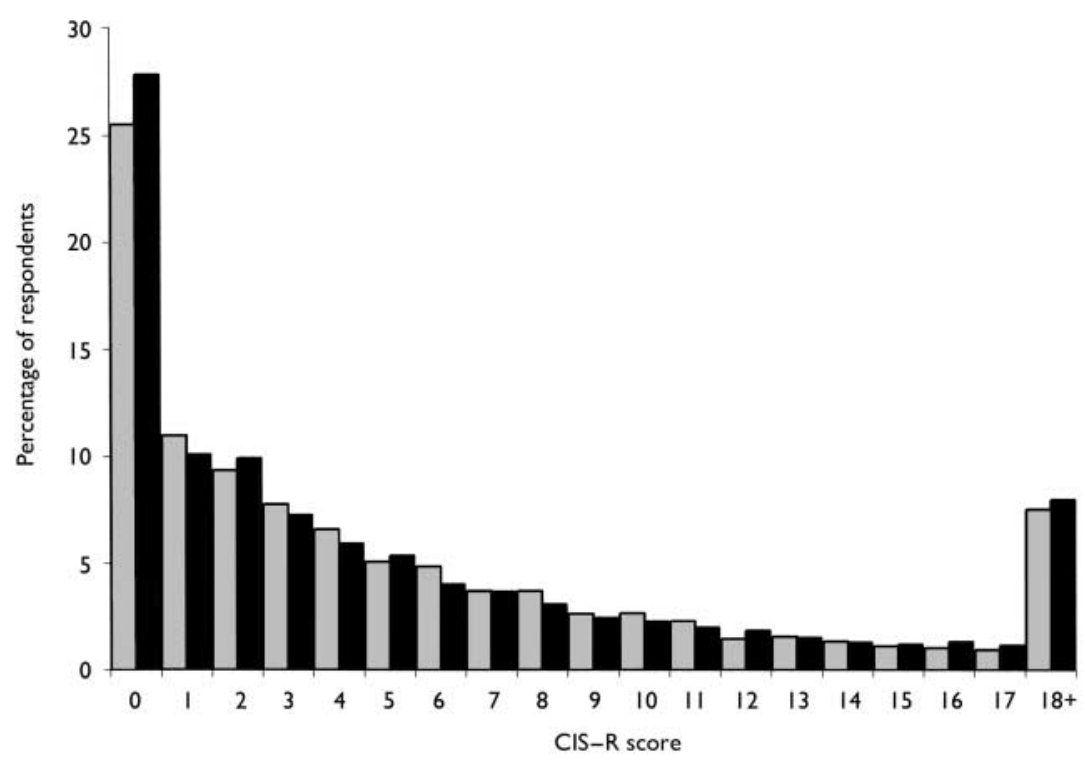

Fig. I Revised Clinical Interview Schedule (CIS-R) scores in the $1993(\square)$ and 2000 ( $\square$ ) surveys.

surveys. Therefore, an optimistic view would be that the interventions in people with no psychiatric disorder were prophylactic and hence clinically appropriate. An alternative is that it represents unnecessary treatment in the wake of a reduction in prescribing thresholds and the growing availability of antidepressants with fewer sideeffects. The survey also found a small but disturbing rise in the use of hypnotics and anxiolytics, despite the well-known addictive properties of these drugs and despite psychological therapy being the treatment of choice for anxiety disorders (Marks, 1992). Data from the GPRD register show a static picture, with no increase in the prescribing of such agents. Despite the increases in general practitioner contact and prescribing for mental health reasons, there was little increase in the provision of psychological interventions over a period in which the policy focus on psychological treatments was tentative and that on prevention almost non-existent. Thus, attention persistently focused on prescribing behaviour may bring about change in one sector, but not necessarily in other, less vigorously targeted areas.

Large-scale health surveys can describe service and treatment utilisation, both overall and in specific subgroups. They can be used to establish an initial baseline, followed up after intervals sufficient for progress to be expected by further surveys using identical methods. The effectiveness of mental health policy might then be evaluated in at least two ways: first, by demonstrating increased delivery of evidence-based intervention, and second, by demonstrating achieved health gain.

It might be assumed that increased use of prescribed psychotropic medication would improve the mental health of the nation. However, despite a distinct advance in treatment with medication, there has been no detectable reduction in population prevalence. The use of repeat surveys may not be capable of demonstrating a health gain of this type. For example, if $11 \%$ more of those with mental disorder received antidepressants and the number needed to treat in order for one patient to benefit was about 7 (Bech et al, 2000), only $1.5 \%$ more would improve as a result of medication alone. This has a negligible effect on population prevalence. The problem is compounded because efficacy data from randomised trials of short-term use of antidepressive drugs for acute depression suggest that their advantage is no longer apparent after several months of followup. There is a growing realisation and acceptance that clinically significant depression has high rates of recurrence and chronicity and therefore needs to be managed more as a chronic than an acute disorder (Brugha, 1995; Andrews, 2001). Thus, the long-term use of antidepressive medication to reduce relapse might lead to a significant reduction in overall prevalence.

Recent attempts to increase the effectiveness of primary mental health care may also help explain our findings on the stability of prevalence. Evaluations of interventions to improve the primary care of depression show little impact on outcome (Mann et al, 1998; Thompson et al, 2000), save for a very few exceptions (Schulberg et al, 1998; Simon et al, 2000). These more effective interventions provide considerably enhanced patient-clinician contact and attention to treatment adherence, often using contact with practice nurses over prolonged periods. Further efficacy trials looking at such complex interventions for neurotic disorders should be conducted within different primary care systems, including Great Britain.

The apparent lack of attributable health gain found in our study also serves as a reminder of the limitations of policy strategies based almost exclusively on the treatment of identified cases. For example, the effect of a ninefold increase in antidepressant sales over the years 1975 to 2000 in Iceland was not associated with reductions in suicide rates or out-patient visits (Helgason et al, 2004). A similar difficulty is apparent when attempts are made to demonstrate the effect of health care on mortality using aggregate data (Mackenbach et al, 1990). It has been argued that public health strategy must include prevention and promotion policies for the whole population (Rose, 1993) in addition to specific treatments for established mental disorders. Our two surveys found that socio-economic risk factors such as unemployment and low social support improved only slightly between 1993 and 2000 (Meltzer et al, 2002), both in the healthy population and in those with identified psychiatric disorders. We therefore do not know what impact substantial socioeconomic change would have on rates of mental disorder. Our results emphasise that an effective health policy requires increased investment in prevention as well as in primary care mental health services (Department of Health, 1999).

Standardised survey methods have a vital part to play in evaluating wider social, health and economic impacts as well as in health surveillance. The surveys in 1993 and 2000 benefit from the use of identical measures and directly comparable sampling designs. There is a small possibility that changes in the use and in the understanding of questionnaire language and in the effects of social desirability on respondents over the intervening years might have reduced comparability. However, the stability of prevalence we found is consistent with a recent analysis of period-cohort effects in psychological distress, using two post-war 
UK birth cohorts followed into adulthood, which concluded that there was evidence of age and cohort effects but little support for period effects on psychological distress over time (Sacker \& Wiggins, 2002).

The surveys reported here also suffered from the general decline in response rates in household surveys throughout the world over the past decade. Moreover, by definition, observational research does not control intervention and service implementation, and unknown or unmeasured confounders may be masking valuable information on effects. Non-experimental study designs cannot rule out coincident increases in risk of a disorder and in effective treatment that mask health gain. Neither can we rule out the possibility that increased treatment in the 'non-case' group represents health gains without which prevalence might have increased. The limitations of the present approach to evaluating the effectiveness of health policy call for complementary research strategies. For example, effectiveness might be demonstrable with accurately monitored records of health status and treatment in cohorts at elevated risk (Brugha, 1995). Experimental approaches to policy implementation are being increasingly recommended to governments (Anonymous, 2002), although political objection to selective policy implementation may sometimes be an obstacle.

Our key finding is of a modest improvement in the pharmacological management of common mental disorder over this 7-year period. The considerable undertreatment of depression and related common mental disorders has been reduced. However, there has been no comparable progress in providing psychological therapies. Psychological treatments might reduce chronicity and relapse, and hence prevalence (Marks, 1992; Roth \& Fonagy, 1996). Health service users have long demanded more choice in treatment, in particular greater access to psychological and psychosocial interventions. Because of their high prevalence, depression and anxiety disorders must be managed in primary care, and these surveys add to the argument for the implementation of care (Vonkorff $\&$ Goldberg, 2001). Medicines need to be used appropriately and within an overall management plan that is tailored to the individual and that includes social and psychological interventions and advice for patients and their families, as needed. This approach has been advocated in the UK

\section{CLINICAL IMPLICATIONS}

- Widespread increased prescribing of psychotropic medication has not improved the mental health of the nation.

- New and more effective approaches to the management of depression in primary care need to be widely disseminated.

- The potential benefits of structured psychological therapies in primary care have yet to be realised.

\section{LIMITATIONS OF THE STUDY}

- Although data on 16000 adults were used in this study, there may have been limited statistical power to detect the small and short-term benefits of increased prescribing of antidepressants.

- Observational data on health and service utilisation trends may not be easily amenable to rigorous policy evaluation.

- The potential value of observing psychiatric morbidity trends may have been masked by the lack of substantial socio-economic change over the 7-year interval between these two national surveys.

TRAOLACH S. BRUGHA, PhD, MRCPsych, Department of Health Sciences, University of Leicester; PAUL E. BEBBINGTON, PhD, FRCPsych, Department of Mental Health Sciences, Royal Free and University College Medical School, London; NICOLA SINGLETON, MSc, Social Survey Division, Office for National Statistics, London; DAVID MELZER, MB, BCh, Department of Community Medicine, Institute of Public Health, University of Cambridge; RACHEL JENKINS, FRCPsych, WHO Collaborating Centre, Institute of Psychiatry, London; GLYN LEWIS, PhD, FRCPsych, Division of Psychiatry, University of Bristol; MICHAEL FARRELL, MRCPsych, DINESH BHUGRA, PhD, FRCPsych, Institute of Psychiatry, London; ALISON LEE, MSc, HOWARD MELTZER, PhD, Social Survey Division, Office for National Statistics, London, UK

Correspondence: DrT. S. Brugha, Brandon Mental Health Unit, Leicester General Hospital, Gwendolen Road, Leicester LE5 4PW,UK. Tel: 0225 6295; fax: 0225 6235; e-mail: tsb@le.ac.uk

(First received 4 December 2003, final revision 27 May 2004, accepted 26 June 2004)

adaptation of the World Health Organization primary care guidelines (Jenkins, 2004).

\section{ACKNOWLEDGEMENT}

Field work and data collection were funded by the Department of Health, London.

\section{REFERENCES}

Andrews, G. (200I) Should depression be managed as a chronic disease? BMJ, 332, 419-421.

Anonymous (2002) A way forward for US health care? (editorial). Lancet, 360, 1709

Bebbington, P. E. \& Nayani, T. (1995) The psychosis screening questionnaire. International Journal of Methods in Psychiatric Research, 5, II-20.
Bech, P., Cialdella, P., Haugh, M. C., et al (2000) Meta-analysis of randomised controlled trials of fluoxetine $v$. placebo and tricyclic antidepressants in the short-term treatment of major depression. British journal of Psychiatry, 176, 421-428.

\section{British Medical Association \& Roya} Pharmaceutical Society of Great Britain (2000) British National Formulary. London \& Wallingford: BMJ Books \& Pharmaceutical Press.

Brugha, T. S. (1995) Depression undertreatment: lost cohorts, lost opportunities? (editorial). Psychological Medicine, 25, 3-6.

Department of Health (1999) National Service Frameworks for Mental Health. Modern Standards and Service Models. London: Department of Health.

Donoghue, J., Tylee, A. \& Wildgust, H. (1996) Cross sectional database analysis of antidepressant prescribing in general practice in the United Kingdom, 1993-5. BMJ Clinical Research Edition, 313, 861-862.

Ferriman, A. (200I) Levels of neurosis remained static in the 1990s. BMJ Clinical Research Edition, 323, 130. 
Goldberg, D. \& Huxley, P. (1992) Common Mental Disorders. A Bio-social Model. London: Routledge.

\section{Helgason, T., Tómasson, H. \& Zoega, T. (2004)}

Antidepressants and public health in Iceland: time serie analysis of national data. British Journal of Psychiatry, $\mathbf{1 8 4}$ 157-162.

Jenkins, R. (ed.) (2004) WHO Guide to Mental and Neurological Health in Primary Care. London: Royal Society of Medicine.

Jenkins, R., Lewis, G., Bebbington, P., et al (1997) The national psychiatric morbidity surveys of Great Britain - initial findings from the household survey. Psychological Medicine, 27, 775-789.

Jenkins, R., McCulloch, A., Friedli, L., et al (2002) Developing a National Mental Health Policy. Maudsley Monographs no. 43. Hove: Psychology Press.

Lewis, G., Pelosi, A. J., Araya, R., et al (1992) Measuring psychiatric disorder in the community: a standardised assessment for use by lay interviewers. Psychological Medicine, 22, 465-486.

Mackenbach, J. P., Bouvier-Colle, M. H. \& Jougla, E. (1990) 'Avoidable' mortality and health services: a review of aggregate data studies. Journal of Epidemiology and Community Health, 44, I06-III.

Mann, A. H., Blizard, R., Murray, J., et al (1998) An evaluation of practice nurses working with general practitioners to treat people with depression. British Journal of General Practice, 48, 875-879.
Marks, I. (1992) Innovations in mental health care delivery. British Journal of Psychiatry, 160, 589-597.

Meltzer, H., Singleton, N., Lee, A., et al (2002)

Comparison of the economic and social characteristic of adults with neurotic disorders, 1993 and 2000. In The Social and Economic Circumstances of Adults with Mental Disorders (ed. Office for National Statistics Social Survey Division), pp. 66-70. London: ONS.

Office for National Statistics (2000) Key Health Statistics from General Practice 1998. Analyses of Morbidity and Treatment Data, Including Time Trends, England and Wales. MB6 No. 2, 175. London: ONS.

Paykel, E. S., Tylee, A., Wright, A., et al (1997) The Defeat Depression Campaign: psychiatry in the public arena. American Journal of Psychiatry, I54, 59-65.

Rose, G. (1993) Mental disorder and the strategies of prevention. Psychological Medicine, 23, 553-555.

Roth, A. \& Fonagy, P. (1996) What Works for Whom? London: Guilford.

Sacker, A. \& Wiggins, R. D. (2002) Age-periodcohort effects on inequalities in psychological distress, 1981-2000. Psychological Medicine, 32, 977-990.

Schulberg, H. C., Katon, W., Simon, G. E., et al (1998) Treating major depression in primary care practice. An update of the Agency for Health Care Policy and Research practice guidelines. Archives of General Psychiatry, 55, II2I-II27.
Simon, G. E., Vonkorff, M., Rutter, C., et al (2000) Randomised trial of monitoring, feedback, and management of care by telephone to improve treatment of depression in primary care [In Process Citation]. BM] Clinical Research Edition, 320, 550-554.

Singleton, N., Bumpstead, R., O'Brien, M., et al (200I) Psychiatric Morbidity Among Adults Living in Private Households. National Statistics I54. London: Stationery Office.

STATA (1999) Stata Statistical Software, Release 6.0. College Station, TX: STATA Corp.

Thompson, C., Kinmonth, A. L., Stevens, L., et al (2000) Effects of a clinical-practice guideline and practice-based education on detection and outcome of depression in primary care: Hampshire Depression Project randomised controlled trial. Lancet, $\mathbf{3 5 5}$ |85-19|.

Vonkorff, M. \& Goldberg, D. (200I) Improving outcomes in depression. The whole process of care needs to be enhanced. BM], 323, 948-949.

Wing, J. K., Babor, T., Brugha, T., et al (1990) SCAN: Schedules for Clinical Assessment in Neuropsychiatry. Archives of General Psychiatry, 47, 589-593.

World Health Organization (1993) The ICD-I0 Classification of Mental and Behavioural Disorders: Diagnostic Criteria for Research. Geneva: WHO. 